according to the DRB1 genotypes, DMA*0104 was increased in DRB1*15/16, DRB1*03 negative patients.

Conclusion These data show an association between SLE susceptibility and DMA*0103, *0104, DMB*0102. The influence of these alleles cannot be explained by linkage disequilibrium with SLE-associated alleles.

\section{FRI0120 VALVULAR ABNORMALITIES IN SLE IS STRONGLY RELATED TO ARTERIAL DISEASE}

${ }^{1}$ EK Svenungsson, ${ }^{2} \mathrm{~K}$ Jensen-Urstad, ${ }^{3} \mathrm{U}$ De Faire, ${ }^{1} \mathrm{~J}$ Frostegård. ${ }^{1}$ Department of Rheumatology; ${ }^{2}$ Department of Clinical Physiology, Karolinska Hospital; ${ }^{3}$ Division of Cardiovascular-Epidemiology, Institute of Environmental Medicine, Stockholm, Sweden

\subsection{6/annrheumdis-2001.155}

Background In patients with SLE of long duration cardiovascular disease is the most important cause of increased mortality. Valvular lesions are common in SLE patients but it has not been studied how these abnormalities relate to arterial disease in general in SLE.

Objectives To study cardiac heart and valve function in SLE patients with and without arterial disease and to compare these groups to each other and to population controls.

Methods Twenty-six women and two men (mean age $53 \pm 8$ years) with SLE and arterial disease (objectively verified history of myocardial infarction, angina, cerebral infarction or intermittent claudication) (SLE cases) were compared to SLE patients with no signs of arterial disease (SLE controls) and to population controls. The three groups were matched for age and gender. Echocardiography was performed on all together with a thorough clinical and laboratory evaluation.

Results 15/28 SLE cases had cardiac valvular abnormalities. Three of these had undergone valve replacement, one had a significant aortic insufficiency, and the other eleven had thickening of valvular leaflets of no measurable haemodynamic importance. Only $1 / 28$ SLE controls and 2/28 population controls had similar valvular thickening. Among SLE cases those with valvular abnormalities had significantly higher levels of plasma homocysteine $(\mathrm{p}<0.0001)$, orosomucoid $(\mathrm{p}=0.05)$, plasma triglycerides $(\mathrm{p}=0.02)$ and the cholesterol fraction of very low-density lipoproteins (VLDL) $(p=0.01)$. There was no association with antiphospholipid antibodies (antibodies to cardiolipin IgG, cardiolipin IgM, b2 glykoprotien-1 or lupus anticoagulant).

Conclusion SLE patients with arterial disease have a high prevalence of valvular abnormalities 54\%. The most common abnormality is diffuse valvular thickening. In SLE patients without clinical signs of arterial disease valve abnormalities are as uncommon as in age matched population controls. Hyperhomocysteinemia and dyslipidemia, both of which have been linked to endothelial dysfunction, correlated strongly with valvular abnormalities. It is thus possible that valvular thickening in SLE patients may be a manifestation of endothelial damage, which needs further attention and prospective clinical evaluation.

\section{FRI0121 ANTI-ENDOTHELIAL CELL AUTO-ANTIBODIES AND SOLUBLE MARKERS OF ENDOTHELIAL CELL DYSFUNCTION IN SYSTEMIC LUPUS ERYTHEMETOSUS} ${ }^{1} \mathrm{R}$ Dupuy, ${ }^{2} \mathrm{~F}$ Resplandy, ${ }^{2} \mathrm{M}$ Seigneur, ${ }^{1} \mathrm{~T}$ Schaeverbeke, ${ }^{3} \mathrm{~J}$ Constans, ${ }^{2} \mathrm{MR}$ Boisseau,
${ }^{3} \mathrm{C}$ Conri. ${ }^{1}$ Rheumatology; ${ }^{2}$ Haematology; ${ }^{3}$ Internal Medicine, CHU Bordeaux, Bordeaux,
France

10.1136/annrheumdis-2001.156

Background In systemic lupus erythematosus (SLE), disease severity may be related to factors such as endothelial cell damage.

Objectives We tested the hypothesis that anti-endothelial cell antibodies (AECA) and plasma markers of endothelial cell dysfunction would be related to disease severity in SLE.

Methods Accordingly we measured AECA by human umbilical vein endothelial cell binding, endothelial markers von Willebrand factor, soluble thrombomodulin, soluble E-selectin by ELISA, and disease severity by SLEDAI and SLICC/ACR in 35 patients with SLE.

Results Despite high levels of IgG AECA ( $p<0.001$ ), compared to 21 healthy controls, we found a positive correlation only between IgG AECA and the SLEDAI index $(\mathrm{r}=0.393, \mathrm{p}=$ 0.021). We did?t find elevation of soluble markers of endothelial cell dysfunction compared to healthy controls.

Conclusion We conclude that IgG AECA seem to be related to disease activity in SLE, possibly in a pathogenic rôle. Conversely, plasma markers of endothelial cell damage seem to be an epiphenomenon and may only be related to excess inflammation in these patients.

\section{FRI0122 ANTI-RO/LA ANTIBODIES AND CUMULATIVE TISSUE DAMAGE (SLICC/ACR) IN PATIENTS WITH SYSTEMIC LUPUS ERYTHEMATOSUS}

${ }^{1} \mathrm{~L}$ Carreño, ${ }^{1} \mathrm{FJ}$ López-Longo, ${ }^{2} \mathrm{M}$ Rodríguez-Mahou, ${ }^{1} \mathrm{CM}$ González, ${ }^{1} \mathrm{Al}$ Turrión, ${ }^{1} \mathrm{CA}$ Montilla, ${ }^{1} \mathrm{M}$ Moreno-Zazo, ${ }^{1} \mathrm{~N}$ Caro, ${ }^{1} \mathrm{R}$ Del Castillo, ${ }^{1} \mathrm{C}$ González-Montagut, 'L Cebrián, 'I Monteagudo. 'Rheumatology; ${ }^{2}$ Immunology, Hospital General Universitario, Madrid, Spain

\subsection{6/annrheumdis-2001.157}

\section{Background}

Objectives To calculate SLICC/ACR score for a cohort of patients with systemic lupus erythematosus (SLE) and evaluate its relation with the presence of anti-ENA antibodies (U1-RNP, $\mathrm{Sm}$, Ro, and $\mathrm{La}$ ), anticardiolipin antibodies, and clinical activity at the onset of the disease.

Methods We calculated the SLICC scores of 236 patients diagnosed as SLE between 1988 and 2000. Anti-ENA antibodies were studied by ELISA in the first available serum sample of each patient. The SLE disease activity index (SLEDAI) of the first hospital study was calculated retrospectively.

Results The mean age of our patients was 39 years (SD 15.8) and the mean duration of disease was 9.7 years (SD 6.9). Eightynine percent of the study population were women (211 of 239). Ninety-six patients (40.7\%) scored zero, 90 (38.1\%) scored 1 or 2 , and $50(21.2 \%)$ scored over 2 . The main disorders were renal (66; 28\%), neuropsychiatric $(52 ; 22 \%)$, musculoskeletal (36; $15,3 \%)$, and vascular $(35 ; 14.8 \%)$. The SLICC score obtained at 